\section{$\sqrt{ }$ \\ EDITOR'S CHOICE \\ Effects of intensive glucose control on platelet reactivity in patients with acute coronary syndromes. Results of the CHIPS Study ("Control de Hiperglucemia y Actividad Plaquetaria en Pacientes con Síndrome Coronario Agudo")}

\author{
David Vivas, ${ }^{1}$ Juan C García-Rubira, ${ }^{1}$ Esther Bernardo, ${ }^{1}$ Dominick J Angiolillo, ${ }^{1}$ \\ Patricia Martín, ${ }^{2}$ Alfonso Calle-Pascual, ${ }^{2}$ Iván Núñez-Gil,, ${ }^{1}$ Carlos Macaya, ${ }^{1}$ \\ Antonio Fernández-Ortiz ${ }^{1}$
}

\begin{abstract}
- An additional appendix is published online only. To view this file please visit the journal online (http://heart.bmj.com).

${ }^{1}$ Cardiovascular Institute, San Carlos University Hospital, Madrid, Spain

${ }^{2}$ Department of Endocrinology, San Carlos University Hospital, Madrid, Spain
\end{abstract}

\section{Correspondence to}

Dr David Vivas, Cardiovascular Institute, San Carlos University Hospital, Profesor Martin Lagos s/n 28040, Madrid, Spain; dvivas@secardiologia.es

Accepted 8 February 2011 Published Online First 4 March 2011

\begin{abstract}
Objectives Hyperglycaemia has been associated with increased platelet reactivity and impaired prognosis in patients with acute coronary syndrome (ACS). Whether platelet reactivity can be reduced by lowering glucose in this setting is unknown. The aim of this study was to assess the functional impact of intensive glucose control with insulin on platelet reactivity in patients admitted with ACS and hyperglycaemia.
\end{abstract}

Methods This is a prospective, randomised trial evaluating the effects of either intensive glucose control (target glucose $80-120 \mathrm{mg} / \mathrm{dl}$ ) or conventional control (target glucose $180 \mathrm{mg} / \mathrm{dl}$ or less) with insulin on platelet reactivity in patients with ACS and hyperglycaemia. The primary endpoint was platelet aggregation following stimuli with $20 \mu \mathrm{M}$ ADP at $24 \mathrm{~h}$ and at hospital discharge. Aggregation following collagen, epinephrine and thrombin receptor-activated peptide, as well as $\mathrm{P}_{2} \mathrm{Y}_{12}$ reactivity index and surface expression of glycoprotein IIb/llla and P-selectin were also measured. Results Of the 115 patients who underwent random assignment, 59 were assigned to intensive and 56 to conventional glucose control. Baseline platelet functions and inhospital management were similar in both groups. Maximal aggregation after ADP stimulation at hospital discharge was lower in the intensive group $(47.9 \pm 13.2 \%$ vs $59.1 \pm 17.3 \% ; p=0.002$ ), whereas no differences were found at $24 \mathrm{~h}$. Similarly all other parameters of platelet reactivity measured at hospital discharge were significantly reduced in the intensive glucose control group. Conclusions In this randomised trial, early intensive glucose control with insulin in patients with ACS presenting with hyperglycaemia was found to decrease platelet reactivity.

Clinical Trial Registration Number http://www. controlledtrials.com/ISRCTN35708451/ ISRCTN35708451.

Hyperglycaemia is a strong predictor of short and long-term adverse events in patients presenting with acute coronary syndrome (ACS) ${ }^{1-3}$ Several mechanisms have been proposed to explain hyperglycaemia-mediated adverse outcomes, including increased expression of tissue factor and metalloproteinases or enhanced levels of inflammatory markers. ${ }^{4} 5$ Moreover, high platelet reactivity has also been documented in patients with hyperglycaemia in whom an increased synthesis of thromboxane $\mathrm{A}_{2}$ and alteration of both $\mathrm{P}_{2} \mathrm{Y}_{12}$ dependent and independent aggregation pathways have been reported. ${ }^{7}$ This adverse effect observed for hyperglycaemia has led to several studies aimed at assessing the clinical impact of aggressive glycaemic control with insulin on clinical outcomes. Results from these studies have been controversial, because intensive glycaemic control has been associated with severe episodes of hypoglycaemia and a worse prognosis. ${ }^{8}$ Therefore, to date the optimal management of hyperglycaemia in acute settings remains a topic of debate. ${ }^{9-14}$

In patients with ACS, platelets play a crucial role, particularly in the early phases of the disease. ${ }^{15}$ Previous studies have shown that insulin infusion in patients with ACS and hyperglycaemia improves platelet responsiveness to nitric oxide and reduces oxidative stress, ${ }^{16-19}$ but to date there are no specifically designed prospective randomised studies assessing the influence of blood glucose control on platelet aggregation and activation in patients hospitalised for ACS. Therefore, the present study aims to evaluate a wide range of functional measurements of platelet reactivity in patients presenting with ACS and hyperglycaemia, and hypothesises that the use of an algorithm for intensive blood glucose control with insulin would result in reduced platelet reactivity.

\section{METHODS}

\section{Study population}

This is an open single-centre, prospective, randomised trial evaluating the effects of intensive glucose control with insulin on platelet function in patients with ACS and hyperglycaemia. Patients were enrolled if they were admitted to the coronary care unit of our hospital with a diagnosis of ACS within the preceding $24 \mathrm{~h}$ combined with either known diabetes mellitus and blood glucose at admission greater than $120 \mathrm{mg} / \mathrm{dl}(6.6 \mathrm{mmol} / \mathrm{l})$, or unknown diabetes mellitus with glucose level greater than $160 \mathrm{mg} / \mathrm{dl}(8.8 \mathrm{mmol} / \mathrm{l})$ or between 120 and 160 at admission and greater than $120 \mathrm{mg} /$ $\mathrm{dl} 1 \mathrm{~h}$ later. ACS and diabetes mellitus were defined according to the current clinical guidelines. ${ }^{20} 21$ 
Exclusion criteria included patients on mechanical ventilation at study evaluation, unclear origin of chest pain, refusal to participate, unable to follow-up, concomitant enrolment in other studies, women of childbearing age and/or blood glucose at admission of $400 \mathrm{mg} / \mathrm{dl}(22.2 \mathrm{mmol} / \mathrm{l})$ or greater. The study complied with the Declaration of Helsinki and it was approved by the ethical committee of the San Carlos University Hospital. All patients gave their written informed consent to participate in the study.

\section{Study design and randomisation}

Patients were randomly allocated in a 1:1 fashion to the intensive glucose control group with a glucose target of $80-120 \mathrm{mg} / \mathrm{dl}$ $(4.4-6.6 \mathrm{mmol} / \mathrm{l})$ or to the conventional control group with a glucose target of $180 \mathrm{mg} / \mathrm{dl}(10.0 \mathrm{mmol} / \mathrm{l})$ or less. To achieve these goals, patients on the intensive group received an insulin infusion during the initial $24 \mathrm{~h}$ according to a predefined algorithm modified from the DIGAMI protocol ${ }^{10}$ and elaborated together with the diabetes unit of our centre (see supplementary appendix, available online only). Thereafter patients in this group received a daily subcutaneous ultra-slow insulin administration supplemented with rapid-acting insulin for meals. Patients in the conventional group received rapid-acting insulin using a sliding scale algorithm to obtain the target glucose level, in addition patients previously treated with insulin received their usual insulin dosage. All capillary glucose levels were measured by finger stick testing (Accu-Chek Sensor, Roche Diagnostic S.L., Mannheim, Germany).

All subjects underwent standard cardiology care, including, unless contraindicated, a loading dose of aspirin and clopidogrel on admission, followed by $100 \mathrm{mg}$ aspirin and $75 \mathrm{mg}$ clopidogrel a day. Use of glycoprotein IIb/IIIa inhibitors and the choice of anticoagulant were left to the criteria of the treating physician. Concomitant treatments, such as $\beta$-blockers, ACE inhibitors and statins were used according to current clinical guidelines. ${ }^{20}{ }^{21} \mathrm{All}$ included patients were intended to undergo early, or emergent when needed, coronary angiography followed by percutaneous coronary intervention when indicated using standard techniques and equipment.

\section{Platelet function testing}

Blood sampling for platelet function assays was collected from an antecubital vein using a 21-gauge needle before assigned insulin treatment (baseline) $24 \mathrm{~h}$ after treatment and at hospital discharge. The first $3 \mathrm{ml}$ blood were discharged to avoid spontaneous platelet activation. All samples were processed within $1 \mathrm{~h}$ by physicians who were blinded to the glucose control group assignment.

\section{Platelet aggregation}

Platelet aggregation was assessed using light transmittance aggregometry (LTA) as previously described. ${ }^{22}$ In brief, LTA was performed in platelet-rich plasma by the turbidimetric method in a four-channel aggregometer (Chrono-Log 490 Model; Chrono-Log Corp., Havertown, Pennsylvania, USA) according to standard protocols. The platelet-rich plasma was obtained as a supernatant after centrifugation of citrated blood at $800 \mathrm{rpm}$ for $10 \mathrm{~min}$, and platelet-poor plasma was obtained after a second centrifugation of samples at $2500 \mathrm{rpm}$ for $10 \mathrm{~min}$. Light transmission was adjusted to $0 \%$ with platelet-rich plasma and to $100 \%$ with platelet-poor plasma for each measurement. Curves were recorded during $5 \mathrm{~min}$ and platelet aggregation was determined as the maximal percentage change in light transmittance using platelet-poor plasma as a reference. $\mathrm{ADP} 5$ and $20 \mu \mathrm{M}$ were used to assess $\mathrm{P}_{2} \mathrm{Y}_{12}$-dependent pathway aggregation, while collagen $6 \mu \mathrm{g} / \mathrm{ml}$ and epinephrine $20 \mu \mathrm{M}$ were used to assess $\mathrm{P}_{2} \mathrm{Y}_{12}$-independent pathway aggregation, and thrombin receptor-activated peptide (TRAP) $25 \mu \mathrm{M}$ to assess thrombin-dependent platelet aggregation.

\section{Platelet $\mathrm{P}_{2} \mathrm{Y}_{12}$ reactivity index}

The platelet $\mathrm{P}_{2} \mathrm{Y}_{12}$ reactivity index (PRI) was determined through the assessment of vasodilator-stimulated phosphoprotein (VASP) phosphorylation according to standard protocols. ${ }^{23}$ In brief, VASP phosphorylation was measured by quantitative flow cytometry (Coulter EPICS XL-MCL system II software) using commercially available labelled monoclonal antibodies (Biocytex Inc., Marseille, France). The PRI was calculated after measuring the mean fluorescence intensity of VASP phosphorylation levels following challenge with prostaglandin $E_{1}$ and prostaglandin $\mathrm{E}_{1}$ plus $\mathrm{ADP}$. Prostaglandin $\mathrm{E}_{1}$ increases VASP phosphorylation levels through stimulation of adenylate cyclase while ADP binding to purinergic receptors leads to the inhibition of adenylate cyclase. Therefore, the addition of $\mathrm{ADP}$ to prostaglandin $\mathrm{E}_{1}$-stimulated platelets reduces levels of prostaglandin $\mathrm{E}_{1}$-induced VASP phosphorylation. Elevated PRI values are indicative of the upregulation of the $\mathrm{P}_{2} \mathrm{Y}_{12}$ signalling pathway.

\section{Platelet glycoprotein Ilb/Illa activation and P-selectin expression}

Platelet surface expression of activated glycoprotein IIb/IIIa was assessed using PAC1 (PAC1-FITC conjugated; Becton Dickinson, Rutherford, New Jersey, USA) antibodies as previously described. ${ }^{24}$ P-selectin surface expression was assessed using a phycoerythrin-conjugated anti-CD62P $(0.3 \mathrm{mg} / \mathrm{ml}$; Becton Dickinson, San Jose, California, USA) antibody. Both glycoprotein IIb/IIIa and P-selectin expression were assessed before and after the addition of ADP $10 \mu \mathrm{M}$. Samples were analysed within $2 \mathrm{~h}$ by flow cytometry using Coulter EPICS XL-MCL flow cytometer system II software. Platelet activation was expressed as the percentage of platelets positive for antibody binding.

\section{Primary endpoint and sample size calculation}

The primary endpoint of the study was the percentage of maximal aggregation following stimulus with ADP $20 \mu \mathrm{M}$ using LTA assessed at $24 \mathrm{~h}$ and at hospital discharge. We hypothesised a $10 \%$ mean reduction in the primary endpoint following intensive compared with conventional glucose control with a SD of the differences between the two groups of $15 \%$. Therefore, at least 48 patients per group would be required to provide a $90 \%$ power to detect a statistical difference between groups with a two-sided $\alpha$ level of 0.05 . Estimation of platelet function values was based on previous reports in patients with diabetes. ${ }^{7} 22$ Secondary endpoints included the percentage of maximal platelet aggregation following stimulus with collagen, epinephrine and TRAP, as well as the measurement of PRI and activated glycoprotein IIb/ IIIa and P-selectin surface expression.

\section{Statistical analysis}

The Kolmogorov-Smirnov test was used to analyse the normal distribution of continuous variables. Normally distributed variables are presented as mean $\pm \mathrm{SD}$ and were compared using Student's t test. Variables that did not follow a normal distribution are presented as median and IOR and were compared with the Mann-Whitney $U$ test. Categorical variables are expressed as frequencies and percentages, and were compared with the $\chi^{2}$ test or the Fisher's exact test when at least $25 \%$ of 
values showed an expected cell frequency below five. A logistic regression analysis was performed to identify the independent contribution of intensive glucose control in platelet aggregation profiles after adjustment for potential confounder variables (those with statistically significant differences in the univariate model). All probability values reported are two-sided, and a value of $p<0.05$ was considered to be significant. Statistical analysis was performed using SPSS version 15.0 software.

\section{RESULTS}

Between March 2007 and July 2009, 440 patients admitted to our coronary care unit had ACS presenting with hyperglycaemia and met the inclusion criteria for the study. Of these, 139

Table 1 Baseline characteristics according to treatment group

\begin{tabular}{|c|c|c|c|}
\hline & $\begin{array}{l}\text { Intensive } \\
\text { glucose control } \\
(n=59)\end{array}$ & $\begin{array}{l}\text { Conventional } \\
\text { glucose control } \\
(n=56)\end{array}$ & p Value \\
\hline Age (years) & $66.9 \pm 12.0$ & $67.5 \pm 12.2$ & 0.77 \\
\hline Male, n (\%) & $37(62.7)$ & $36(64.3)$ & 0.86 \\
\hline \multicolumn{4}{|l|}{ Risk factors, n (\%) } \\
\hline Current smoking & $20(33.9)$ & $15(26.8)$ & 0.41 \\
\hline Hypertension & $40(67.8)$ & $42(75.0)$ & 0.39 \\
\hline Dyslipidaemia & $29(49.2)$ & $29(51.8)$ & 0.78 \\
\hline Known diabetes mellitus & $39(66.1)$ & $33(60.0)$ & 0.50 \\
\hline Obesity (BMI > $30 \mathrm{~kg} / \mathrm{m}^{2}$ ) & 20 (33.9) & $24(42.9)$ & 0.32 \\
\hline \multicolumn{4}{|l|}{ Medical history, $\mathrm{n}(\%)$} \\
\hline Previous MI & $13(22.0)$ & $13(23.2)$ & 0.88 \\
\hline Previous $\mathrm{PCl}$ & $8(13.6)$ & $11(19.6)$ & 0.38 \\
\hline Previous stroke & $2(3.4)$ & $0(0.0)$ & 0.26 \\
\hline Symptomatic PVD & $7(11.9)$ & $8(14.3)$ & 0.70 \\
\hline Chronic kidney disease & $5(8.5)$ & $4(7.1)$ & 0.53 \\
\hline \multicolumn{4}{|c|}{ Previous diabetes mellitus treatment, $\mathrm{n}(\%)$} \\
\hline Metformin & $16(27.1)$ & $12(21.4)$ & 0.52 \\
\hline Sulphonylureas & $10(16.9)$ & $8(14.3)$ & 0.80 \\
\hline $\begin{array}{l}\text { Others (thiazolidinediones, } \\
\text { incretin mimetics) }\end{array}$ & $2(3.4)$ & $1(1.8)$ & 0.59 \\
\hline Insulin & $12(20.3)$ & $12(21.4)$ & 0.89 \\
\hline \multicolumn{4}{|l|}{ Clinical presentation, n (\%) } \\
\hline STEMI & $33(55.9)$ & $21(37.5)$ & 0.05 \\
\hline Anterior STEMI & $15(25.4)$ & $8(14.5)$ & 0.15 \\
\hline Killip class $\geq 2$ & $23(39.0)$ & $24(43.6)$ & 0.61 \\
\hline GRACE score $\geq 140$ & $37(62.7)$ & $33(60.0)$ & 0.77 \\
\hline \multicolumn{4}{|l|}{ Laboratory data } \\
\hline $\begin{array}{l}\text { Baseline glucose (mg/dl), } \\
\text { median (IQR) }\end{array}$ & $181(152-243)$ & $180(140-223)$ & 0.92 \\
\hline $\mathrm{HbA} 1 \mathrm{c}(\%)$ & $7.3 \pm 1.7$ & $7.4 \pm 1.8$ & 0.64 \\
\hline Haematocrit (\%) & $38.8 \pm 5.7$ & $38.5 \pm 6.3$ & 0.73 \\
\hline Platelet count $\left(1000 / \mathrm{mm}^{3}\right)$ & $214.9 \pm 85.1$ & $229.3 \pm 56.7$ & 0.29 \\
\hline Creatinine clearance $(\mathrm{ml} / \mathrm{min})^{*}$ & $76.1 \pm 33.7$ & $77.2 \pm 32.6$ & 0.85 \\
\hline Peak CK (UI/I), median (IOR) & $977(318-2096)$ & $502(165-1333)$ & 0.03 \\
\hline $\begin{array}{l}\text { Peak troponin I (ng/ml), } \\
\text { median (IQR) }\end{array}$ & $25.7(5.9-79.9)$ & $16.1(4.8-33.3)$ & 0.08 \\
\hline \multicolumn{4}{|l|}{ Angiographic characteristics, $\mathrm{n}(\%)$} \\
\hline Coronary angiography & $58(98.3)$ & $54(96.4)$ & 0.47 \\
\hline $\begin{array}{l}\text { No of narrowed }(\geq 50 \%) \\
\text { coronary arteries }\end{array}$ & $1.7 \pm 0.7$ & $1.7 \pm 0.8$ & 0.97 \\
\hline Left anterior descending & $33(55.9)$ & $33(60.0)$ & 0.66 \\
\hline Left circumflex & $26(44.1)$ & $30(54.5)$ & 0.26 \\
\hline Right coronary & $30(50.8)$ & $35(63.6)$ & 0.17 \\
\hline Multivessel disease & $31(52.5)$ & $33(60.0)$ & 0.42 \\
\hline No significant coronary narrowing & $6(10.2)$ & $1(1.8)$ & 0.07 \\
\hline
\end{tabular}

${ }^{*}$ Assessed by de Crockcroft and Gault formula.

$\mathrm{BMI}$, body mass index; $\mathrm{CAD}$, coronary artery disease; $\mathrm{CK}$, creatinine kinase; GRACE, Global Registry of Acute Cardiac Events; HbA1c, glycated haemoglobin A1c; MI, myocardial infarction; PCl, percutaneous coronary intervention; PVD, peripheral vascular disease; STEMI, ST-elevation myocardial infarction.
Table 2 Inhospital management and adverse outcomes according to treatment group

\begin{tabular}{|c|c|c|c|}
\hline & $\begin{array}{l}\text { Intensive } \\
\text { glucose } \\
\text { control }(n=59)\end{array}$ & $\begin{array}{l}\text { Conventional } \\
\text { glucose } \\
\text { control }(n=56)\end{array}$ & p Value \\
\hline Interval to blood glucose target (h) & $7.8 \pm 2.1$ & $8.3 \pm 2.5$ & 0.21 \\
\hline $\begin{array}{l}\text { Patients kept on range throughout } \\
\text { the study, } \mathrm{n}(\%)\end{array}$ & $46(78.0)$ & $34(60.7)$ & 0.035 \\
\hline $\begin{array}{l}\text { Blood glucose at } 24 \mathrm{~h}(\mathrm{mg} / \mathrm{dl}) \text {, } \\
\text { median (IQR) }\end{array}$ & $115(90-152)$ & $157(129-210)$ & $<0.001$ \\
\hline $\begin{array}{l}\text { Insulin requirements during } \\
\text { initial } 24 \mathrm{~h} \text { (IU) }\end{array}$ & $58.8 \pm 38.4$ & $18.2 \pm 12.6$ & $<0.001$ \\
\hline $\begin{array}{l}\text { No of capillary tests during } \\
\text { initial } 24 \mathrm{~h}\end{array}$ & $16.7 \pm 4.0$ & $6.7 \pm 1.4$ & $<0.001$ \\
\hline Hypoglycaemia $<60 \mathrm{mg} / \mathrm{dl}, \mathrm{n}(\%)$ & $22(37.3)$ & $1(1.7)$ & $<0.001$ \\
\hline $\begin{array}{l}\text { Severe hypoglycaemia }<40 \mathrm{mg} / \mathrm{dl} \text {, } \\
\mathrm{n}(\%)\end{array}$ & $2(3.4)$ & $0(0.0)$ & 0.26 \\
\hline $\begin{array}{l}\text { Blood glucose at discharge }(\mathrm{mg} / \mathrm{dl}) \text {, } \\
\text { median (IQR) }\end{array}$ & $103(87-130)$ & $141(122-202)$ & $<0.001$ \\
\hline \multicolumn{4}{|l|}{$\begin{array}{l}\text { Coronary revascularisation } \\
\text { procedures, } \mathrm{n}(\%)\end{array}$} \\
\hline $\mathrm{PCl}$ with drug-eluting stent & $25(42.4)$ & $23(41.8)$ & 0.95 \\
\hline $\mathrm{PCl}$ with bare-metal stent & $11(18.6)$ & $9(16.4)$ & 0.75 \\
\hline Fibrinolysis & $8(13.6)$ & $5(9.1)$ & 0.45 \\
\hline CABG & $3(5.1)$ & $6(10.9)$ & 0.21 \\
\hline No revascularisation & $12(20.3)$ & $11(20.0)$ & 0.96 \\
\hline \multicolumn{4}{|c|}{ Drug therapy during hospitalisation, n (\%) } \\
\hline Aspirin & $58(98.3)$ & $52(94.5)$ & 0.28 \\
\hline \multicolumn{4}{|l|}{ Clopidogrel } \\
\hline $600 \mathrm{mg}$ loading dose & $28(47.5)$ & $23(41.1)$ & 0.49 \\
\hline $300 \mathrm{mg}$ loading dose & $19(32.2)$ & $20(35.7)$ & 0.69 \\
\hline No loading dose & $12(20.3)$ & $13(23.2)$ & 0.44 \\
\hline $75 \mathrm{mg}$ maintenance dose & $49(83.1)$ & $47(85.5)$ & 0.72 \\
\hline Glycoprotein Ilb/llla inhibitors & $33(55.9)$ & $34(61.8)$ & 0.52 \\
\hline Unfractioned heparin & $27(45.8)$ & $23(42.6)$ & 0.73 \\
\hline Enoxaparin & $30(50.8)$ & $29(53.7)$ & 0.76 \\
\hline$\beta$-Blockers & $44(74.6)$ & $44(80.0)$ & 0.49 \\
\hline ACE inhibitors/ARB & $49(83.1)$ & $47(85.5)$ & 0.72 \\
\hline Statins & $57(96.6)$ & $50(90.9)$ & 0.19 \\
\hline \multicolumn{4}{|l|}{ Adverse inhospital outcomes, n (\%) } \\
\hline Death & $2(3.4)$ & $3(5.4)$ & 0.53 \\
\hline Re-infarction & $2(3.4)$ & $3(5.4)$ & 0.53 \\
\hline $\begin{array}{l}\text { Repeated target-vessel } \\
\text { revascularisation }\end{array}$ & $1(1.7)$ & $3(5.4)$ & 0.28 \\
\hline Cardiogenic shock & $1(1.7)$ & $5(9.1)$ & 0.09 \\
\hline Complete AV block & $2(3.4)$ & $3(5.4)$ & 0.47 \\
\hline Major bleeding* & $1(1.7)$ & $2(3.6)$ & 0.47 \\
\hline Minor bleeding* & $3(5.1)$ & $5(9.1)$ & 0.32 \\
\hline Days in CCU, median (IQR) & $2(2-3)$ & $2(2-3)$ & 0.61 \\
\hline Days in hospital, median (IOR) & $7(6-11)$ & $7(6-9)$ & 0.89 \\
\hline
\end{tabular}

${ }^{*}$ According to the TIMI classification. ${ }^{25}$

$\mathrm{ARB}$, angiotensin receptor blocker; $\mathrm{AV}$, auriculo-ventricular; $\mathrm{CABG}$, coronary artery bypass graft; CCU, coronary care unit; $\mathrm{PCl}$, percutaneous coronary intervention.

patients were not included due to inability to perform the baseline and the 24-h time point platelet function analysis during the weekend, 123 due to unwillingness to participate and 63 patients were already included in another clinical trial. Finally, a total of 115 patients was enrolled into the trial, of which 59 were randomly assigned to the intensive control and 56 to the conventional glycaemic control groups. Baseline demographics, clinical characteristics, laboratory data and angiographic findings of both groups are shown in table 1 . There were no significant differences between groups except for patients assigned to intensive glucose control, who were more likely to present at admission with an ST-segment elevation myocardial infarction and, consequently, had a higher creatine kinase peak elevation. In addition, demographic and clinical 
parameters for patients included in the CHIPS trial were not different to those of ACS patients admitted to the coronary care unit with hyperglycaemia and not included in the study (data not shown).

\section{Inhospital management and outcomes}

Blood glucose parameters, revascularisation procedures, drugs used during hospitalisation and inhospital cardiovascular events were not different between the two treatment groups (table 2). According to treatment assignment, intensive control resulted in a significant reduction in glucose levels at $24 \mathrm{~h}$ compared with conventional control (115 (90-152) vs 157 (129-210) mg/dl; $\mathrm{p}<0.001)$, and at discharge $(103(87-130)$ vs $141(122-202)$ $\mathrm{mg} / \mathrm{dl} ; \mathrm{p}<0.001)$. Both groups achieved their blood glucose target within a similar time frame, but a higher proportion of patients with intensive control remained on target throughout the entire study compared with patients with conventional control $(78.0 \%$ vs $60.7 \% ; p=0.035)$. Patients with intensive control received larger amounts of insulin (58.8 \pm 38.4 vs 18.2 $\pm 12.6 \mathrm{IU} ; \mathrm{p}<0.001)$ and a higher number of capillary glucose tests were performed during the initial $24 \mathrm{~h}(16.7 \pm 4.0$ vs $6.7 \pm 1.4 ; p<0.001)$. Hypoglycaemic episodes of less than $60 \mathrm{mg} / \mathrm{dl}$ (3.78 mmol/l) occurred more frequently with the intensive than the conventional glucose control $(37.1 \%$ vs $1.7 \% ; \mathrm{p}<0.001)$. Severe hypoglycaemia of less than $40 \mathrm{mg} / \mathrm{dl}$ $(2.2 \mathrm{mmol} / \mathrm{l})$ was rare and occurred in two patients with intensive control versus none with conventional glucose control $(p=0.26)$. No sequels from hypoglycaemia were reported in any patient. Blood glucose management and levels according to treatment group are summarised in table 2 .

\section{Platelet reactivity $24 \mathrm{~h}$ after random assignment}

No differences in platelet reactivity were found at baseline, before insulin treatment assignment, or between the intensive and the conventional control groups (table 3). At $24 \mathrm{~h}$ after random assignment, the extensive use of glycoprotein IIb/IIIa inhibitors was associated with a marked platelet inhibition and no differences in the primary endpoint among groups was observed (maximal aggregation after ADP $20 \mu \mathrm{M} 28.9 \pm 22.6 \%$ in the intensive control vs $31.9 \pm 22.7 \%$ in the conventional control group; $p=0.23$ ). However, a significant decrease in maximal aggregation was found when platelets were stimulated with TRAP $25 \mu \mathrm{M}$, and also a significant decrease in activated glycoprotein IIb/IIIa receptors and P-selectin surface expression was found at $24 \mathrm{~h}$ in the intensive compared with the conventional control group (table 3 ). When assessing patients not on glycoprotein IIb/IIIa inhibitors at the time of the ' 24 h' platelet assessment (40 patients in the intensive and 31 in the conventional control group), maximal aggregation after ADP $20 \mu \mathrm{M}$ was significantly reduced with intensive glucose control (37.5 \pm 18.9 vs $46.9 \pm 15.1 \% ; \mathrm{p}=0.033$ ), and similarly platelet reactivity was significantly reduced in the intensive group when assessed by any other of the evaluated parameters (maximal aggregation after ADP $5 \mu \mathrm{M}: 20.0 \pm 14.9$ vs $30.6 \pm 16.1 \%$; $p=0.01$; after collagen $6 \mu \mathrm{g} / \mathrm{ml}$ : $23.4 \pm 20.5$ vs $39.7 \pm 23.1 \%$; $\mathrm{p}=0.03$; after epinephrine $20 \mu \mathrm{M}$ : $18.9 \pm 15.2$ vs $28.2 \pm 16.6 \%$; $=0.04$; after TRAP $25 \mu \mathrm{M}$ : $52.2 \pm 20.1$ vs $64.0 \pm 12.1 \% ; \mathrm{p}=0.02$; VASP phosphorylation by PRI: $50.8 \pm 21.8$ vs $66.7 \pm 19.8 \%$; $p=0.04$; glycoprotein IIb/IIIa activation after ADP $10 \mu \mathrm{M}$ : $36.4 \pm 24.8$ vs $55.0 \pm 24.9 \% ; \mathrm{p}=0.02$; P-selectin expression after ADP $10 \mu \mathrm{M}$ : $46.4 \pm 21.9 \%$ vs $58.8 \pm 23.0 \%$; $p=0.04$; intensive vs conventional control group, respectively). Figure 1 shows the early effects (at $24 \mathrm{~h}$ ) of intensive blood glucose control on the various parameters of platelet reactivity measured in patients not on glycoprotein IIb/IIIa inhibitors at the time of platelet function assessment.

\section{Platelet reactivity at hospital discharge}

The primary endpoint of the study was significantly reduced at hospital discharge in patients assigned to intensive blood glucose control (maximal aggregation after ADP $20 \mu \mathrm{M}: 47.9 \pm 13.2 \%$ in the intensive vs $59.1 \pm 17.3 \%$ in the conventional control group; $\mathrm{p}=0.002$ ). Similarly, maximal aggregation after ADP $5 \mu \mathrm{M}$, collagen $6 \mu \mathrm{g} / \mathrm{ml}$, epinephrine $20 \mu \mathrm{M}$ and TRAP $25 \mu \mathrm{M}$ were significantly reduced at hospital discharge in patients managed with intensive control compared with those managed with conventional glucose control (table 3). Moreover, platelet activation assessed with the PRI, glycoprotein IIb/IIIa surface activation and P-selectin expression was also significantly reduced at hospital discharge in the intensive control group (table 3). Figure 2 shows the differential effects of intensive blood glucose control compared with conventional control on the various parameters of platelet reactivity measured at hospital discharge.

Although our study was not powerful enough to reach definitive conclusions, we have also analysed the subgroup of patients with 'known diabetes mellitus' $(\mathrm{n}=72)$ and found that the decrease in platelet reactivity following intensive treatment was better seen in this subgroup of known diabetes mellitus patients compared with those without 'known diabetes mellitus' (figure 3).

Table 3 Platelet function profiles at baseline, $24 \mathrm{~h}$ and hospital discharge

\begin{tabular}{|c|c|c|c|c|c|c|c|c|c|}
\hline & \multicolumn{3}{|l|}{ Baseline } & \multicolumn{3}{|l|}{$24 \mathrm{~h}$} & \multicolumn{3}{|l|}{ Discharge } \\
\hline & $\begin{array}{l}\text { Intensive } \\
\text { glucose } \\
\text { control }(n=59)\end{array}$ & $\begin{array}{l}\text { Conventional } \\
\text { glucose } \\
\text { control }(n=56)\end{array}$ & p Value & $\begin{array}{l}\text { Intensive } \\
\text { glucose } \\
\text { control }(n=59)\end{array}$ & $\begin{array}{l}\text { Conventional } \\
\text { glucose } \\
\text { control }(n=56)\end{array}$ & p Value & $\begin{array}{l}\text { Intensive } \\
\text { glucose } \\
\text { control }(n=59)\end{array}$ & $\begin{array}{l}\text { Conventional } \\
\text { glucose } \\
\text { control }(n=56)\end{array}$ & p Value \\
\hline ADP $5 \mu \mathrm{M}$ & $23.2 \pm 24.3$ & $23.8 \pm 24.2$ & 0.89 & $15.2 \pm 15.5$ & $20.3 \pm 17.8$ & 0.06 & $30.3 \pm 12.8$ & $40.1 \pm 18.8$ & 0.01 \\
\hline ADP $20 \mu \mathrm{M}$ & $34.0 \pm 28.1$ & $34.2 \pm 30.3$ & 0.97 & $28.9 \pm 22.6$ & $31.9 \pm 22.7$ & 0.23 & $47.9 \pm 13.2$ & $59.1 \pm 17.3$ & 0.002 \\
\hline Collagen $6 \mu \mathrm{g} / \mathrm{ml}$ & $25.6 \pm 30.6$ & $28.3 \pm 29.8$ & 0.66 & $18.3 \pm 20.4$ & $25.9 \pm 24.8$ & 0.11 & $34.1 \pm 21.4$ & $45.5 \pm 25.8$ & 0.04 \\
\hline \multicolumn{10}{|l|}{ Platelet activation (\%) } \\
\hline PRI & $64.2 \pm 23.4$ & $63.3 \pm 20.7$ & 0.88 & $56.4 \pm 26.7$ & $55.6 \pm 27.8$ & 0.45 & $47.4 \pm 19.4$ & $56.6 \pm 21.9$ & 0.05 \\
\hline P-selectin expression & $39.0 \pm 31.5$ & $45.0 \pm 32.5$ & 0.33 & $47.9 \pm 20.9$ & $56.8 \pm 21.6$ & 0.05 & $48.7 \pm 20.9$ & $57.4 \pm 21.2$ & 0.02 \\
\hline $\begin{array}{l}\text { Glycoprotein Ilb/Illa (PAC) } \\
\text { expression }\end{array}$ & $59.0 \pm 23.2$ & $59.7 \pm 22.5$ & 0.88 & $32.9 \pm 25.8$ & $44.7 \pm 29.1$ & 0.05 & $46.6 \pm 20.4$ & $55.5 \pm 23.5$ & 0.04 \\
\hline
\end{tabular}

PRI, platelet P2Y 12 reactivity index; TRAP, thrombin receptor-activated peptide. 

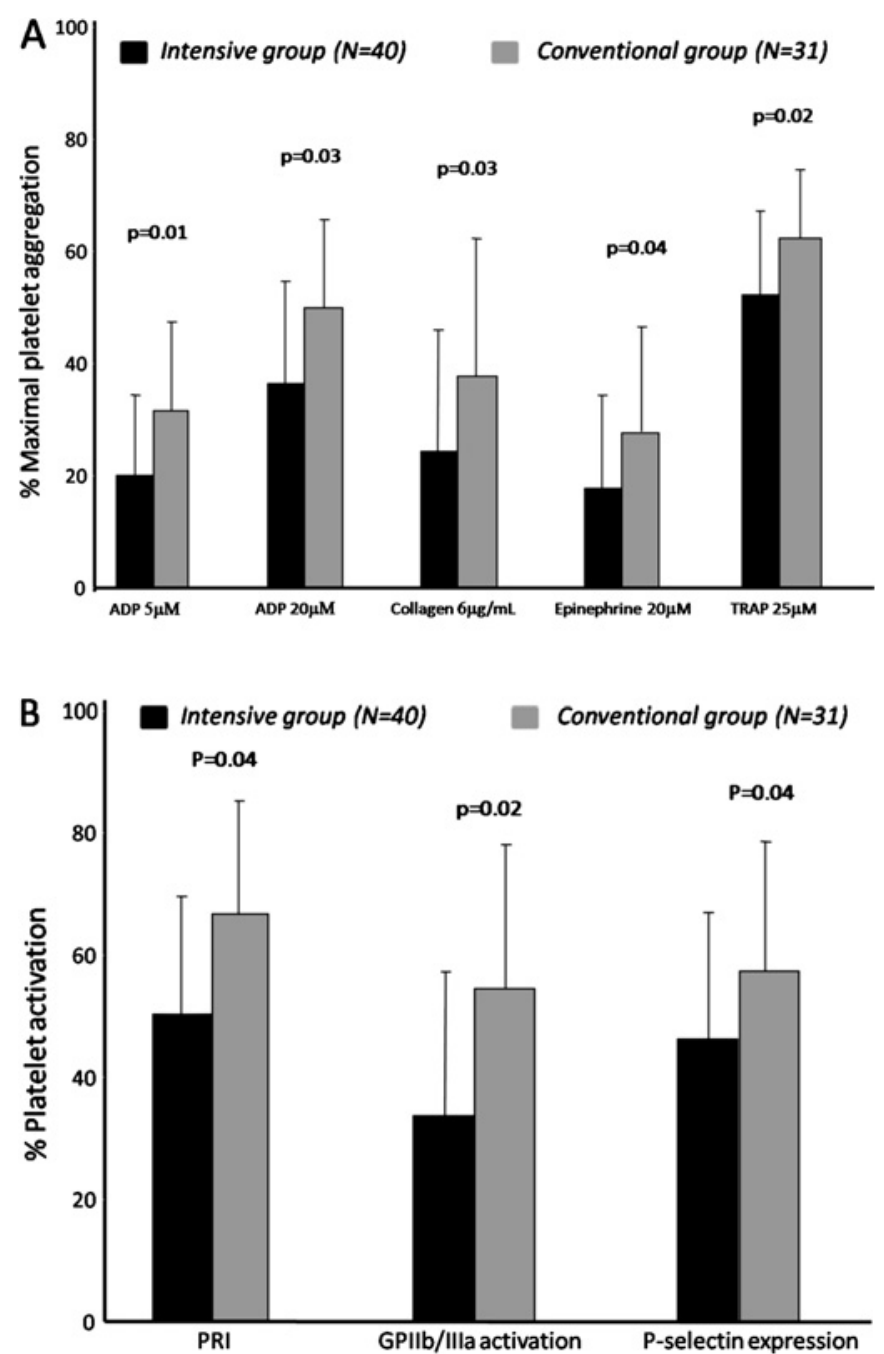

Figure 1 Platelet reactivity in patients not on glycoprotein Ilb/lla inhibitors $24 \mathrm{~h}$ after random assignment. (A) Percentage of maximal platelet aggregation following ADP $(5$ and $20 \mu \mathrm{M})$, collagen $6 \mu \mathrm{g} / \mathrm{ml}$, epinephrine $20 \mu \mathrm{M}$ and thrombin receptor-activated peptide (TRAP) $25 \mu \mathrm{M}$ stimuli. (B) Platelet $\mathrm{P}_{2} \mathrm{Y}_{12}$ reactivity index (PRI), glycoprotein (GP) $\mathrm{Ilb} / \mathrm{llla}$ activation and P-selectin expression induced by ADP $10 \mu \mathrm{M}$ expressed as a percentage of positive platelets. Errors bars representative SD of the mean.

\section{DISCUSSION}

This randomised prospective study is the first to show that intensive blood glucose control with a target of $80-120 \mathrm{mg} / \mathrm{dl}$ during the early phases of presentation of patients having ACS and hyperglycaemia is associated with a marked reduction in platelet reactivity. This effect was observed across a wide range of platelet function tests suggesting that multiple platelet signalling pathways are influenced by the blood glucose treatment strategy. As platelets were aggressively inhibited using the early administration of intravenous glycoprotein IIb/IIIa inhibitors in a high proportion of patients $(>50 \%)$, we believe that the measurement of ADP $20 \mu \mathrm{M}$ induced maximal aggregation chosen to validate the study hypothesis at $24 \mathrm{~h}$ was not sensitive enough to find differences among the intensive and the conventional control group at this early time point. In fact, when using a more potent agonist for platelet aggregation (TRAP $25 \mu \mathrm{M}$ ), or when using more sensitive assays (glycoprotein IIb/IIIa activation and P-selectin expression) at $24 \mathrm{~h}$, we did find a significant reduction in platelet reactivity in the intensive
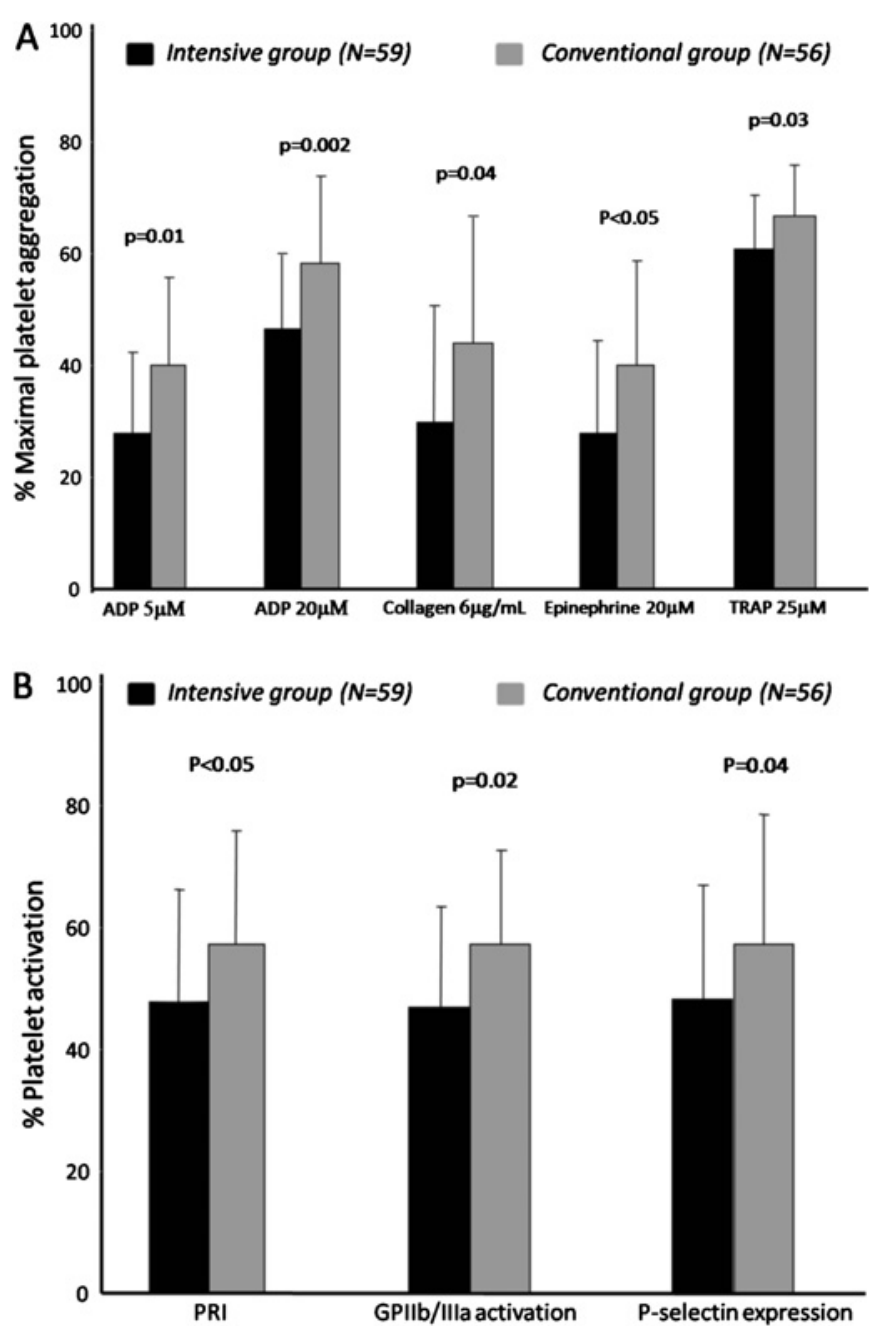

Figure 2 Platelet reactivity in patients treated with insulin infusion compared with conventional treatment at hospital discharge. (A) Percentage of maximal platelet aggregation following ADP ( 5 and $20 \mu \mathrm{M})$, collagen $6 \mu \mathrm{g} / \mathrm{ml}$, epinephrine $20 \mu \mathrm{M}$ and thrombin receptoractivated peptide (TRAP) $25 \mu \mathrm{M}$ stimuli. (B) Platelet $\mathrm{P} 2 \mathrm{Y}_{12}$ reactivity index (PRI), glycoprotein (GP) Ilb/llla activation and P-selectin expression induced by ADP $10 \mu \mathrm{M}$ expressed as a percentage of positive platelets. Errors bars representative SD of the mean.

control group compared with the conventional group. Moreover, an analysis of patients not on glycoprotein IIb/IIIa inhibitors at the time of the ' 24 h' platelet assessment showed a significant and uniform reduction on platelet reactivity for all the performed assays. At hospital discharge, when patients were uniformly managed with dual antiplatelet treatment (aspirin plus clopidogrel), primary endpoint as well as platelet reactivity assessed with any other of the performed assays were significantly reduced in patients managed with intensive glucose control. To date, several studies have shown that platelet reactivity in ACS patients may be a strong predictor of cardiovascular events, including acute and subacute stent thrombosis. ${ }^{26}$ In particular, we have previously shown that patients with diabetes with coronary artery disease and platelet hyperreactivity have an over threefold increase in 2-year cardiovascular event rates. ${ }^{27}$ This underscores the need for defining approaches aimed to reduce platelet reactivity, particularly in high-risk settings such as patients with diabetes mellitus. To this extent, our findings showing reduced platelet reactivity with intensive glycaemic control provide insights into how this strategy may contribute 

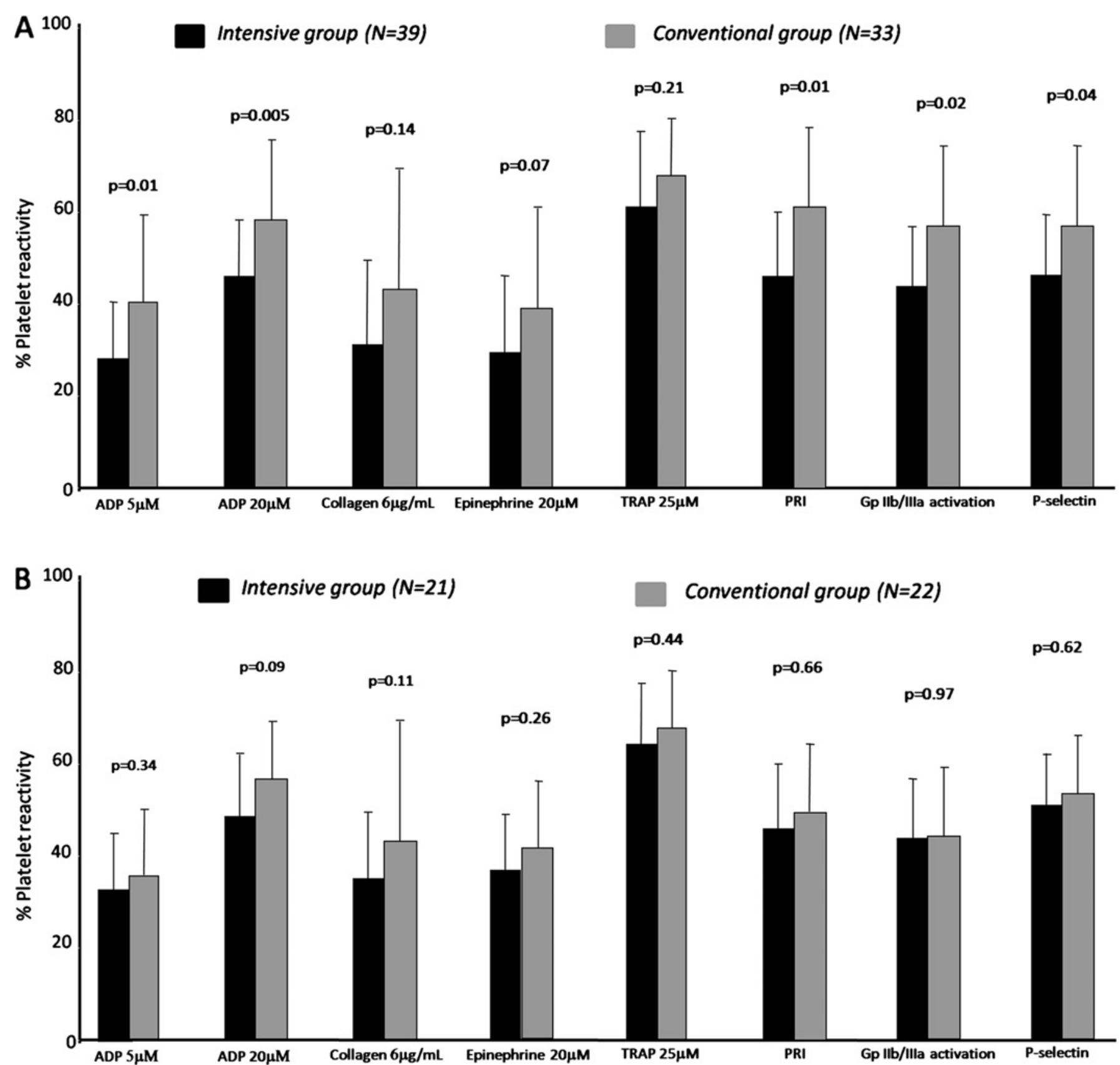

Figure 3 Platelet reactivity assessed at hospital discharge in the subgroup of patients with 'known diabetes mellitus' (A) and without 'known diabetes mellitus' (B). Errors bars representative SD of the mean. GP, glycoprotein; PRI, platelet $P 2 \mathrm{Y}_{12}$ reactivity index; TRAP, thrombin receptoractivated peptide.

to improve the cardiovascular outcome among patients with ACS presenting with hyperglycaemia.

Although a high blood glucose level is one of the most important prognostic predictors of early outcome after ACS, the beneficial effects of intensive glucose control in this setting remain controversial. ${ }^{9-14}$ The DIGAMI-1 trial demonstrated that tight blood glucose control significantly reduced mortality at 1 year in patients with myocardial infarction, ${ }^{10}$ but the use of an optimised subcutaneous insulin regimen for 3 months after discharge in the intensive control group led the authors to hypothesise that the clinical benefit could be due to the postdischarge treatment. A second study, the DIGAMI-2, aimed to address this question ${ }^{11}$ but did not find differences in long-term mortality among the intensive and conventional control groups.
Of note, differences in glucose levels between the intensive and the conservative groups were higher in the DIGAMI-1 (38 mg/dl) than in the DIGAMI-2 study $(16 \mathrm{mg} / \mathrm{dl})$, and this difference in the aggressiveness of treatment might have contributed to the inconsistent results between both studies. In our study, glucose differences obtained between treatment groups were in the range of those seen in the DIGAMI- $142 \mathrm{mg} / \mathrm{dl}$ at $24 \mathrm{~h}$ and $38 \mathrm{mg} / \mathrm{dl}$ at discharge), and the reduction in platelet reactivity with this level of glucose lowering seen in our study might suggest one physiological rationale to explain the clinical benefit seen in the DIGAMI-1 study. Moreover, two recent publications have also provided additional evidence to support the benefit for the early reversal of hyperglycaemia in patients admitted with ACS. A reduction in inflammatory status, 
oxidative stress and post-infarction remodelling has been demonstrated following strict glycaemic control in patients with a first myocardial infarction undergoing coronary bypass surgery, ${ }^{28}$ and improved platelet responsiveness to nitric oxide together with a decreased superoxide generation have been shown after $12 \mathrm{~h}$ of insulin infusion in patients with ACS and hyperglycaemia. ${ }^{19}$

The present work has several limitations. First, it was not aimed to distinguish whether the effects shown with the intensive glucose control on platelet reactivity may be attributed to insulin administration, glucose normalisation, or both. Although other clinical benefits in patients with diabetes mellitus have been related to lowering glucose rather than insulin administration, insulin per se has been shown to reduce platelet aggregation by inhibiting calcium mobilisation induced by ADP or thrombin, as well as platelet-collagen interactions. ${ }^{29}$ In our study, although the benefit on platelet reactivity could seem more related to glucose normalisation, patients in the intensive group received larger amounts of insulin; therefore, this aspect still remains unresolved. Second, our study was not sized to find differences in early events and particularly in hypoglycaemic episodes. Although the results of the NICE-SUGAR, ${ }^{13}$ conducted in critically ill patients, have demonstrated a higher mortality in patients on intensive glucose control mainly attributed to a higher number of severe hypoglycaemic episodes in this group, a recent post-hoc analysis of the DIGAMI-2 trial did not show an association between hypoglycaemic episodes and adverse outcomes. ${ }^{30}$ The lower risk profile and the use of an optimised and dedicated algorithm for lowering glucose in our patients may explain the anecdotic incidence of severe hypoglycaemic episodes seen in our study. Finally, the present study was not designed to evaluate long-term outcomes.

\section{CONCLUSION}

Intensive glucose control with insulin among ACS patients presenting with hyperglycaemia decreases platelet reactivity. This effect is observed as early as $24 \mathrm{~h}$ in patients not on glycoprotein IIb/IIIa inhibitors and is maintained at hospital discharge in the entire population studied. These findings provide additional rationale for the use of an intensive glucose control algorithm with insulin in patients with ACS presenting with hyperglycaemia.

Acknowledgements The authors are grateful to the entire group of nursing staff at the coronary care unit of San Carlos University Hospital (Madrid, Spain). Without their experience, enthusiasm and continuous support, this investigation would not have been possible.

Funding This study was funded by a non-restricted grant from the Fundación Investigación y Desarrollo Area Cardiovascular FIC (Madrid, Spain CIF G-81563801).

Competing interests None.

Patient consent Obtained.

Ethics approval This study complied with the Declaration of Helsinki and was approved by the ethical committee of the San Carlos University Hospital, Madrid, Spain.

Provenance and peer review Not commissioned; externally peer reviewed.

\section{REFERENCES}

1. Capes SE, Hunt D, Malmberg K, et al. Stress hyperglycaemia and increased risk of death after myocardial infarction in patients with and without diabetes: a systematic overview. Lancet 2000;355:773-8.

2. Norhammar AM, Ryden L, Malmberg K. Admission plasma glucose. Independent risk factor for long-term prognosis after myocardial infarction even in nondiabetic patients. Diabetes Care 1999;22:1827-31.
3. Vivas D, Garcia-Rubira JC, Gonzalez-Ferrer JJ, et al. Prognostic value of first fasting glucose measurement compared with admission glucose level in patients with acute coronary syndrome. Rev Esp Cardiol 2008:61:458-64.

4. De Rekeneire N, Peila R, Ding J, et al. Diabetes, hyperglycemia, and inflammation in older individuals: the health, aging and body composition study. Diabetes Care 2006;29:1902-8

5. Esposito K, Nappo F, Marfella R, et al. Inflammatory cytokine concentrations are acutely increased by hyperglycemia in humans: role of oxidative stress. Circulation 2002; 106:2067-72.

6. Ferroni $\mathbf{P}$, Basili S, Falco A, et al. Platelet activation in type 2 diabetes mellitus. J Thromb Haemost 2004;2:1282-91.

7. Angiolillo DJ, Bernardo E, Ramirez C, et al. Insulin therapy is associated with platelet dysfunction in patients with type 2 diabetes mellitus on dual oral antiplatele treatment. J Am Coll Cardiol 2006:48:298-304.

8. Yang SW, Zhou YJ, Hu DY, et al. Association between admission hypoglycaemia and in-hospital and 3-year mortality in older patients with acute myocardial infarction. Heart 2010:96:1444-50.

9. Van den Berghe G, Wouters P, Weekers F, et al. Intensive insulin therapy in the critically ill patients. N Engl J Med 2001;345:1359-67.

10. Malmberg K, Ryden L, Efendic S, et al. Randomized trial of insulin-glucose infusion followed by subcutaneous insulin treatment in diabetic patients with acute myocardial infarction (DIGAMI study): effects on mortality at 1 year. J Am Coll Cardiol 1995;26:57-65.

11. Malmberg K, Ryden L, Wedel H, et al. Intense metabolic control by means of insulin in patients with diabetes mellitus and acute myocardial infarction (DIGAMI 2): effects on mortality and morbidity. Eur Heart J 2005;26:650-61.

12. Wiener RS, Wiener DC, Larson RJ. Benefits and risks of tight glucose control in critically ill adults: a meta-analysis. JAMA 2008:300:933-44.

13. Finfer S, Chittock DR, Su SY, et al; the NICE-SUGAR Study Investigators. Intensive versus conventional glucose control in critically ill patients. $N$ Engl J Med 2009:360:1283-97.

14. Zhao YT, Weng CL, Chen ML, et al. Comparison of glucose-insulin-potassium and insulin-glucose as adjunctive therapy in acute myocardial infarction: a contemporary meta-analysis of randomised controlled trials. Heart 2010:96:1622-6.

15. Davi G, Patrono C. Platelet activation and atherothrombosis. N Engl J Med 2007:357:2482-94.

16. Anfossi G, Massucco P, Mattiello L, et al. Insulin exerts opposite effects on platelet function at physiological and supraphysiological concentrations. Thromb Res 1996:82:57-68.

17. Chaudhuri A, Janicke D, Wilson MF, et al. Anti-inflammatory and profibrinolytic effect of insulin in acute ST-segment-elevation myocardial infarction. Circulation 2004:109:849-54.

18. Visser L, Zuurbier CJ, Hoek FJ, et al. Glucose, insulin and potassium applied as perioperative hyperinsulinaemic normoglycaemic clamp: effects on inflammatory response during coronary artery surgery. Br J Anaesth 2005;95:448-57.

19. Worthley MI, Holmes AS, Willoughby SR, et al. The deleterious effects of hyperglycemia on platelet function in diabetic patients with acute coronary syndromes mediation by superoxide production, resolution with intensive insulin administration. J Am Coll Cardiol 2007;49:304-10.

20. Bassand JP, Hamm CW, Ardissino D, et al. Guidelines for the diagnosis and treatment of non-ST-segment elevation acute coronary syndromes. Task Force for Diagnosis and Treatment of Non-ST-Segment Elevation Acute Coronary Syndromes of European Society of Cardiology. Eur Heart J 2007:28:1598-660.

21. Van de Werf F, Bax J, Betriu A, et al. Management of acute myocardial infarction in patients presenting with persistent ST-segment elevation: the task force on the management of ST-segment elevation acute myocardial infarction of the European Society of Cardiology. Eur Heart J 2008;29:2909-45.

22. Angiolillo DJ, Fernandez-Ortiz A, Bernardo E, et al. Platelet function profiles in patients with type 2 diabetes and coronary artery disease on combined aspirin and clopidogrel treatment. Diabetes 2005;54:2430-5

23. Gurbel PA, Bliden KP, Samara W, et al. Clopidogrel effect on platelet reactivity in patients with stent thrombosis: results of the CREST Study. J Am Coll Cardiol 2005; 46:1827-32.

24. Angiolillo DJ, Fernandez-Ortiz A, Bernardo E, et al. Influence of aspirin resistance on platelet function profiles in patients on long-term aspirin and clopidogrel after percutaneous coronary intervention. Am J Cardiol 2006;97:38-43.

25. TIMI Study Group. Definitions used in TIMI-Trials. http://www.timi.org. (accessed 1 Aug 2009)

26. Geisler T, Zürn C, Simonenko R, et al. Early but not late stent thrombosis is influenced by residual platelet aggregation in patients undergoing coronary interventions. Eur Heart J 2010;31:59-66.

27. Angiolillo DJ, Bernardo $E$, Sabate $M$, et al. Impact of platelet reactivity on cardiovascular outcomes in patients with type 2 diabetes mellitus and coronary artery disease. J Am Coll Cardiol 2007:50:1541-7.

28. Marfella R, Di Filippo C, Portoghese M, et al. Tight glycemic control reduces heart inflammation and remodeling during acute myocardial infarction in hyperglycemic patients. J Am Coll Cardiol 2009;53:1425-36.

29. Ferreira IA, Eybrechts KL, Mocking Al, et al. IRS-1 mediates inhibition of Ca2+ mobilization by insulin via the inhibitory G-protein Gi. J Biol Chem 2004;279:3254-64

30. Mellbin LG, Malmberg K, Waldenström A, et al. Prognostic implications of hypoglycemic episodes during hospitalisation for myocardial infarction in patients with type 2 diabetes: a report from the DIGAMI 2 trial. Heart 2009;95:721-7. 